\title{
The Relationship between Multiple Intelligences and Reading Comprehension of EFL Learners across Genders
}

\author{
Masoud Khalili Sabet \\ English Department, University of Guilan, Iran \\ E-mail: sabetma2002@yahoo.com \\ Marjan Mesbah Kiaee (Corresponding author) \\ University Campus2, University of Guilan, Iran \\ E-mail: marjan_mesbah@hotmail.com
}

Received: 02-12-2015

Accepted: 29-01-2016

Published: 31-01-2016

doi:10.7575/aiac.ijels.v.4n.1p.74

URL: http://dx.doi.org/10.7575/aiac.ijels.v.4n.1p.74

\begin{abstract}
With developments in psychology and cognitive sciences in recent years, the significance of individual differences in L2 pedagogy has been highlighted. One of the outcomes of attending to individual differences is the increased attention to the concept of multiple intelligences and its relationship with language learning and different skills including reading comprehension skill. On the same line, the present study aimed at investigating the relationship between multiple intelligences of a group of L2 learners and their reading comprehension ability. To this purpose, 157 medical students studying at the Guilan University of Medical Sciences participated in the study. The instruments utilized were Multiple Intelligences Developmental Assessment Scales (MIDAS) and a reading comprehension test. The findings revealed that among the components of multiple intelligences of the medical students verbal-linguistic intelligence was prevalent. Furthermore, results of Pearson correlation demonstrated a positive but weak relationship between medical students' MI and their reading comprehension ability. The findings also indicated that there is no difference between male and female medical students except in naturalistic intelligence. These findings further pinpoint the importance of attending to multiple intelligences of L2 learners and devising lessons which take their individual differences into account.
\end{abstract}

Keywords: Multiple intelligences, reading comprehension, medical students, gender, EFL

\section{Introduction}

One of the prevalent topics within language teaching and especially within the realm of teaching English as a foreign or second language is attending to the learners' individual differences. This has resulted in the consideration of the whole individual with his needs, strengths, and pitfalls as being different from one another (Brown, 2001; Cook, 2001). A perspective which contributed to the consideration of individuals as different is the Multiple Intelligences Theory (MIT) which has received noticeable attention from L2 practitioners and SLA researchers in recent years. The concept of intelligence was once regarded as being a single factor known as Intelligence Quotient (IQ) tapping into only verbal and mathematical capacity of the individuals; however, in 1983 and 1999 Howard Gardner proposed the concept of Multiple Intelligences (MI) stating that human intelligence is composed of different elements and people vary according to the degree of these different components. Gardner (1983) argued that children possess different skills, abilities, and preferences and they have unique ways of carrying things out. He further affirmed that children are different in their learning process and representation of knowledge and each have their own learning styles.

The concept of intelligence has evolved from a general factor known as $\mathrm{g}$ factor which represents a one-dimensional approach toward intelligence (Spearman, 1904; as cited in Simmons, 2001). MI as put forward by Gardner (1983, 1999) goes beyond this simplistic view of intelligence and presents a multidimensional picture of this concept with several varied but related facets. Gardner's (1983) list of MI includes, Linguistic, Spatial (Visual), Logical-mathematical, Interpersonal, Intrapersonal, Bodily-kinesthetic, Musical, Naturalistic, and Existential. The last two components, that is, Naturalistic, and Existential intelligences were not among the intelligence types when it was first introduced, and they were later added to the list.

In recent years, many L2 studies have proven the implications and usefulness of applying MI in L2 practices (see for example, Akbari \& Hosseini, 2008; Hajhashemi \& Eng, 2012; Jokar \& Hesabi, 2014; Khooei Oskooei \& Salahshoor, 2014; Rahimi, Sadighi \& Hosseinyfard, 2011; Razmjoo, 2008). These studies have examined the components of MIT and their application in ELT materials or classrooms. In the Iranian EFL context Razmjoo (2008) was among the researchers who acknowledged the positive and beneficial consequences of applying MI in the classrooms. He pointed 
out that if students' strengths and weaknesses in relation to different intelligences become known, the teachers could help learners accommodate their various capabilities with their approaches to learning.

English is a mandatory course in Iranian universities, and every field of study requires the students to take at least one or two General English courses. Medical students should also take a General English course in their first years of studying at university. As English is the language of science and has a key role in disseminating information among scholars in different communities, medical students should also have a good knowledge of the English language. Moreover, they should be able to gain knowledge from reading different books and articles related to their field of study. Accordingly, the main focus of General English courses in Iran is on developing the students' reading comprehension ability and being able to read in English is one of the important concerns in English classes. As such, teachers should help learners in using their individual skills on their way to become better readers.

Reading is regarded as the perception of a written text for understanding its content. This understanding is called reading comprehension (Wiener \& Bazerman, 2006). Gaining sufficient skills in reading comprehension is a necessary requirement of medical students who aim to be able to communicate with people all over the world; it is also needed for doing research or experiments in the medical field. As indicated by Lazear (2004) human beings can be trained to learn everything and make use of their potential by knowing how best to use their intelligences. Furthermore, Mckenzie (2009) believed that both the components of MI and language teaching methodology can result in enhancing L2 learners' motivation and academic achievements. Based on what was mentioned so far, it is worth investigating the extent to which MI have any relationship with reading comprehension ability of medical students and investigate the MI profile of them.

There are many studies focusing on the relationship between MI and language learning of EFL learners; however, few studies have investigated the relation between MI and reading comprehension skill of medical students in an EFL context. Therefore, considering the central role of reading skill in General English classes and its importance in the medical science this study seeks to probe the following research questions:

$\mathrm{RQ}_{1}$. What is the relationship between Iranian medical students' MI and their reading comprehension ability?

$\mathrm{RQ}_{2}$. Are there any significant differences between male and female medical students in terms of their MI profile?

$\mathrm{RQ}_{3}$. Which type of intelligences are predictors of medical students' reading comprehension ability?

\section{Literature review}

As mentioned earlier, the significance of individual differences in the process of language learning has been recently highlighted. There are many studies in the fields of language teaching and also psycholinguistics which have dealt with the interrelation between MI and language pedagogy. In what follows some of these studies are reviewed.

In the study of Gaines and Lehmann (2002), the effect of an MI-based project on reading comprehension skills of a group of learners was examined, with the main focus of identifying major problems faced by the learners in reading texts. The findings revealed that using MI strategies can be helpful in developing the learners' reading comprehension ability, in addition to enhancing the students' academic performance as a whole. In a further study, Mbuva (2003) proved the usefulness of teaching based on MIT and its superiority over the more traditional approaches to teaching. He strongly recommended the application of MI in L2 pedagogy and stated that catering for MI of students can provide a way for taking account of the cognition, language, and culture of each student.

In a further study, Barchard (2003) investigated the degree to which cognitive ability, Emotional Intelligence (EI) and personality domain were predictors of academic success of students majoring in psychology. The results indicated that cognitive ability and personality domain strongly correlate with academic achievement. Moreover, the subscales of EI including emotional understanding, social translation and positive expressivity were found to be predictors of the students' academic achievement.

The effect of MI on reading achievement of a number of fourth grade students was explored in the study of McMahon, Rose, and Parks (2004). The instrument used in this study was Teele Inventory of Multiple Intelligences. The findings revealed that among the intelligences only mathematical intelligence strongly influenced the participants' reading performance, and the other domains of intelligence were found not to correlate with the students' reading comprehension skill.

Concerning gender differences in MI, the study of Loori (2005) which was conducted on 90 EFL learners showed that males have a higher degree of logical-mathematical intelligence. In addition, the findings of Razmjoo (2008) indicated that females make more use of intrapersonal intelligence, and no significant difference was found between males and females with respect to their language success and other types of intelligences.

In a further study by Shearer (2006) it was found that there is a relationship between intrapersonal intelligence and the reading achievement of students with a high reading ability. It was also shown that those with a moderate reading skill are more interpersonally intelligent. Finally, logical-mathematical intelligence was found to be stronger in learners with a low reading ability. 
In a study with a rather different perspective by Akbari and Hosseini (2008), the relationship between language learning strategies used by L2 learners and their MI was investigated. It was revealed that there is a strong association between EFL learners' use of language learning strategies and their MI.

In another study conducted in the Iranian EFL context, Tahriri (2011) probed the effectiveness of applying an MI-based instruction on enhancing EFL learners' language proficiency and achievement. The study also sought to determine EFL teachers' attitudes towards the implementation of MI in L2 classrooms. The findings revealed that teaching based on MI can positively affect students' academic achievement, and 66 percent of the instructors considered the application of MI in L2 classes possible.

Finally, in the study of Barzegar, Mirtabatabaei, and Moradi (2011) the relationship between EFL learners' MI and their performance on reading proficiency items was investigated. Results of correlation analysis showed a weak but positive relationship between these two variables. The findings also indicated that MI was hardly a predictor of the participants' performance on reading proficiency items.

\section{Method}

The present study employs a descriptive ex-post-facto design, in that its main aim was to illuminate the characteristics of a selected group of L2 learners concerning their reading comprehension ability and MI profile. As indicated by Hatch and Farhady (1982), ex-post-facto designs are commonly utilized when the researcher does not determine the participants' inherent features and also does not manipulate the independent variable. Therefore, this design is used when the researcher aims to examine the probable relationship between variables.

\subsection{Participants}

In the present study, 175 university students (males=86, females=71) studying at the Guilan University of Medical Sciences participated. The first language of all the students was Farsi, and they were in the age range of 19-22. The participants were taking a four-unit General English course. The proficiency of the learners was checked before the conduct of the study and 157 students who were at the intermediate level were asked to take part in the study. The participants were chosen based on the convenience sampling, and they were content to take the test and also complete the questionnaire, being assured of the anonymity of their responses.

\subsection{Instruments}

In order to collect the necessary data, three instruments were utilized in the present study. The first instrument was Oxford Placement Test (OPT) used for the purpose of homogenizing the sample. OPT is a well-known proficiency test in ELT research which is validated in various studies, and is shown to be a reliable measurement of EFL learners' language proficiency level. The test is composed of two major sections including language use items and cloze test.

In order to measure the reading comprehension ability of the learners, a researcher-made reading comprehension test was used which included three parts. The first part of the test addressed grammatical knowledge of the students through 25 multiple choice items. Part 2 of the test assessed the vocabulary knowledge of the participants via 15 multiple choice tests of vocabulary. The last part of the test comprised of three rather short reading texts, with themes related to the students' major of study which was Medical science, followed by a number of comprehension questions. As such, the reading comprehension test included 59 items. The reliability of the reading comprehension test was checked by piloting it on 15 medical students whose characteristics were similar to the targeted sample. Conducting test-retest method of assessing reliability, the correlation coefficient of the reading test was shown to be .78 at the alpha level of 0.001 , which seems to be acceptable. Concerning the validity of the reading test, three knowledgeable university professors were asked to check the test against the common standards and their ideas were taken into account in revising the test and making it appropriate for measuring the reading comprehension ability of the learners.

Finally, the last instrument utilized in the present study was Multiple Intelligence Developmental Assessment Scale (MIDAS) questionnaire. As the participants of this study were not very much proficient in English language and in order to ensure the comprehensibility of its items to all the learners, we adopted the translated version of the questionnaire from the study of Pishghadam (2009). The questionnaire is composed of 119 Likert-type questions addressing eight areas of interest, abilities, activities, and skills. It is a self-report medium for assessing the intelligences possessed by individuals. Its completion takes about 35 minutes and the responses range from $a$ to $f$, with $a$ indicating a high degree of possessing an ability and $f$ referring to "not knowing". With respect to the validity of the MIDAS, it was validated by Shearer (1996) proving to be an appropriate instrument for measuring the eight intelligences, with the exception of existential intelligence which was later added to the intelligence types. The reliability of the questionnaire was estimated in the present study by administering it among 15 students with identical characteristics to the main participants and the Chronbach alpha for it at the alpha level of .05 was shown to be .86 which is a reliable indicator.

\subsection{Procedures}

For collecting data in order to fulfill the aims of this study, first OPT was distributed among 172 Medical students of the University of Guilan. Among the students who took the test and based on the results of OPT test, 157 were shown to be at the intermediate level of English language proficiency and they were asked to take part in the other phases of the study. All the participants were ensured that their participation in the study does not have any positive or negative effect on their academic achievement tests and they were told that their responses will be used only for research purposes. 
Thus, they voluntarily took part in the study. Next, the participants were asked to take the reading comprehension test with a time limit of 40 minutes. After one week interval, the MIDAS questionnaire was distributed among the same participants and they were asked to fill it with no time limitation. The reason for not setting any time limitation was to make the learners free to think about the statements and carefully choose the responses which were appropriate to them. The researcher was present at the time of data collection, and whenever necessary due explanations were provided to the learners. It should also be pointed out that using the translated version of MIDAS was a great help, as it clarified every point to the participants and made the comprehension of statements easy for them.

\subsection{Data Analysis}

Both descriptive and inferential statistics were utilized for analyzing data in the present study. After calculating students' scores in the reading comprehension test, their scores in the MIDAS questionnaire were estimated. Then, in order to check the normal distribution of data Kolmogorov- Smirnove Test was run which indicated that students' scores in both the reading test and MIDAS were normally distributed.

The descriptive statistics utilized were mean, standard deviation, and standard error of the means. Pearson correlation test was used in order to check the probable relationship between reading comprehension and the MIDAS questionnaire. Moreover, stepwise Multiple Regression and independent-samples t-test was run on the data to examine whether any of the intelligence types are predictors of the students' reading score and also to investigate whether there are gender differences in this regard, respectively.

\section{Results and discussion}

\subsection{Results of Descriptive Statistics}

This study aimed at examining the relationship between MI and reading comprehension ability of a group of Iranian medial students taking degree courses in General English, and also investigating the effect of gender in this regard. The results of descriptive statistics for multiple intelligence profile of the participants are shown in Table 1. The table represents minimum and maximum scores, mean score, and standard deviation of the learners' scores in each category of the MIDAS.

Table 1. Descriptive statistics of the MI profiles of medical students

\begin{tabular}{lccccc}
\hline Type of intelligences & $\mathrm{N}$ & Minimum & Maximum & Mean & Std. Deviation \\
\hline Musical & 157 & 18.00 & 70.00 & 37.898 & 10.486 \\
Bodily-kinesthetic & 157 & 16.00 & 54.00 & 34.961 & 8.035 \\
Logical-mathematical & 157 & 25.00 & 85.00 & 53.076 & 10.782 \\
Spatial & 157 & 19.00 & 73.00 & 41.496 & 10.865 \\
Linguistic & 157 & 34.00 & 88.00 & $\mathbf{6 0 . 6 1 7}$ & 12.452 \\
Interpersonal & 157 & 30.00 & 86.00 & 58.656 & 11.079 \\
Intrapersonal & 157 & 11.00 & 44.00 & $\mathbf{3 1 . 3 5 0}$ & 6.136 \\
Naturalistic & 157 & 10.00 & 59.00 & 31.738 & 10.473 \\
Total & 157 & 239.00 & 502.00 & 3.501 & 56.180 \\
\hline
\end{tabular}

As indicated in Table 1, the highest mean score is for the verbal-linguistic intelligence $(M=60.61 ; S D=12.45)$; as such this type of intelligence can be regarded as the dominant intelligence among the medical students who participated in this study. The table also shows that intrapersonal intelligence has gained the lowest mean score among the other intelligences $(M=31.35 ; S D=6.13)$.

Table 2 presents the results of Pearson correlation test for investigating the probable relationship between the participants' reading comprehension ability and their multiple intelligences.

Table 2. Results of Pearson Product Moment test on the relationship between reading comprehension test and MIDAS

\begin{tabular}{|c|c|c|c|c|}
\hline Type of intelligences & & Females & Males & Total \\
\hline \multirow[t]{2}{*}{ Musical } & Pearson & .02 & .14 & .18 \\
\hline & $p$-value & .84 & .17 & .10 \\
\hline \multirow[t]{2}{*}{ Bodily-kinesthetic } & Pearson & .09 & .16 & .08 \\
\hline & $p$-value & .44 & .12 & .13 \\
\hline \multirow[t]{2}{*}{ Logical- mathematical } & Pearson & .04 & .12 & .09 \\
\hline & $p$-value & .72 & .27 & .24 \\
\hline \multirow[t]{2}{*}{ Spatial } & Pearson & .10 & .06 & .08 \\
\hline & $p$-value & .37 & .57 & .31 \\
\hline \multirow[t]{2}{*}{ Linguistic } & Pearson & -.01 & .17 & .10 \\
\hline & $p$-value & .84 & .10 & .20 \\
\hline \multirow[t]{2}{*}{ Interpersonal } & Pearson & .28 & .21 & .23 \\
\hline & $p$-value & .01 & .04 & .003 \\
\hline \multirow[t]{2}{*}{ Intrapersonal } & Pearson & .03 & -.10 & -.03 \\
\hline & $p$-value & .78 & .35 & .66 \\
\hline \multirow[t]{2}{*}{ Naturalistic } & Pearson & .15 & .23 & .21 \\
\hline & $p$-value & .20 & .03 & .008 \\
\hline \multirow[t]{2}{*}{ Multiple intelligences } & Pearson & .14 & .20 & .18 \\
\hline & $p$-value & .24 & .056 & .02 \\
\hline
\end{tabular}


As indicated in the Table 2 , there is a weak positive relationship between reading comprehension and interpersonal intelligence in male medical students $(\mathrm{r}=.21, p<.05)$, female medical students $(\mathrm{r}=.28, p<.05)$, and the total students $(\mathrm{r}=.23, p<.05)$. In addition, it is evident in the table that there is a weak and positive relationship between reading skill and naturalistic intelligence in males $(\mathrm{r}=.23, p<.05)$ and in all the learners $(\mathrm{r}=.21, p<.05)$. Eventually, the table shows a weak, positive relationship between reading comprehension skill and students' multiple intelligences as estimated through the MIDAS questionnaire $(\mathrm{r}=.18, p<.05)$.

Table 3 indicates that reading comprehension score of the male students can be predicted from various types of intelligences in the MIDAS using regression model of $19 \%$.

Table 3. Predicting reading comprehension scores based on the scores obtained from MIDAS regarding different intelligence types for males

\begin{tabular}{lllll}
\hline Model & R & R Square & Adjusted R Square & Std. Error of the Estimate \\
\hline 1 & $.436^{\mathrm{a}}$ & .190 & .106 & 7.290 \\
\hline
\end{tabular}

In Table 4 the types of intelligences which can act as predictors of male students' reading comprehension scores are shown. As evident in the table, interpersonal intelligence $($ sig $=.00, p<.05)$ and intrapersonal intelligence $($ sig $=.01, p<$ .05) can predict male students' reading comprehension scores. Between these two intelligence types, interpersonal intelligence is a stronger predictor of male students' reading comprehension score, since beta coefficient for it is .35.

Table 4. Results of multiple regression analysis for male students

\begin{tabular}{|c|c|c|c|c|c|}
\hline \multirow[b]{2}{*}{ Model } & \multicolumn{2}{|c|}{ Unstandardized Coefficients $^{a}$} & \multirow{2}{*}{$\begin{array}{c}\text { Standardized } \\
\text { Coefficients } \\
\text { Beta }\end{array}$} & \multirow[b]{2}{*}{$\mathrm{t}$} & \multirow[b]{2}{*}{ Sig. } \\
\hline & B & Std. Error & & & \\
\hline 1 (Constant) & 15.483 & 5.975 & & 2.591 & .011 \\
\hline musical & .011 & .087 & .016 & .127 & .899 \\
\hline $\begin{array}{l}\text { Bodily- } \\
\text { kinesthetic }\end{array}$ & .096 & .121 & .096 & .790 & .432 \\
\hline $\begin{array}{l}\text { Logical- } \\
\text { mathematical }\end{array}$ & .053 & .092 & .077 & .578 & .565 \\
\hline spatial & -.212 & .120 & -.317 & -1.775 & .080 \\
\hline linguistic & .076 & .110 & .119 & .690 & .492 \\
\hline interpersonal & .239 & .119 & .353 & 2.004 & .049 \\
\hline intrapersonal & -.442 & .182 & -.313 & -2.435 & .017 \\
\hline naturalistic & .159 & .080 & .234 & 1.982 & .051 \\
\hline
\end{tabular}

a. Dependent Variable: Skill_reading

Based on the results of multiple regression analysis, the following formula can be used to predict the reading score of male medical students based on their performance in the MIDAS questionnaire:

Reading comprehension score $=15.48+.23$ (interpersonal intelligence) - .44 (intrapersonal intelligence).

Table 5 shows that reading comprehension score of female students can be predicted with the MIDAS using regression model of $15.7 \%$.

Table 5. Predicting reading comprehension scores based on the scores obtained from MIDAS regarding different intelligence types for females

\begin{tabular}{lllll}
\hline Model & $\mathrm{R}$ & $\mathrm{R}$ Square & Adjusted R Square & Std. Error of the Estimate \\
\hline 1 & $.397^{\mathrm{a}}$ & .157 & .049 & 6.044 \\
\hline a. Predictors: (Constant), naturalistic, musical, interpersonal, bodily-kinesthetic, logical-mathematical, spatial, linguistic, interpersonal
\end{tabular}

In Table 6, results of multiple regression analysis with regard to the types of intelligences which can be used to predict the reading comprehension score of female medical students who participated in the present study are depicted.

Based on the results shown in Table 4.6, it is evident that only interpersonal intelligence ( $\operatorname{sig}=.00, \mathrm{p}<.05$ ) can act as predictor of female learners' reading skill. As such, the predictive formula for female students' reading comprehension score is as follows:

Reading comprehension score $=15.28+.33$ (interpersonal intelligence) 
4.2 Results of Independent Samples T-Test

Table 7 indicates the results of independent samples t-test ran for comparing the mean score of male and female participants in every single component of the MIDAS.

Table 6. Results of multiple regression analysis for female students

\begin{tabular}{|c|c|c|c|c|c|}
\hline & Unstanda & efficients $^{\mathrm{a}}$ & Standardized & & \\
\hline Model & $\mathrm{B}$ & Std. Error & Beta & $\mathrm{t}$ & Sig. \\
\hline 1 (Constant) & 15.282 & 4.986 & & 3.065 & .003 \\
\hline Musical & .044 & .093 & .068 & .476 & .636 \\
\hline $\begin{array}{l}\text { Bodily- } \\
\text { kinesthetic }\end{array}$ & -.069 & .125 & -.094 & -.554 & .581 \\
\hline $\begin{array}{l}\text { Logical- } \\
\text { Mathematical }\end{array}$ & .021 & .097 & .034 & .214 & .832 \\
\hline Spatial & -.029 & .100 & -.047 & -.292 & .772 \\
\hline Linguistic & -.150 & .084 & -.310 & -1.783 & .079 \\
\hline Interpersonal & .337 & .114 & .588 & 2.956 & .004 \\
\hline Intrapersonal & -.099 & .145 & -.109 & -.680 & .499 \\
\hline Naturalistic & .006 & .094 & .009 & .067 & .947 \\
\hline
\end{tabular}

a. Dependent Variable: Skill_reading

Table 7. Results of independent-samples t-test for students' scores on MIDAS based on gender

\begin{tabular}{|c|c|c|c|c|c|}
\hline $\begin{array}{l}\text { Type of } \\
\text { intelligence }\end{array}$ & Gender & No & Std. & $\mathrm{t}$ & $p$-value \\
\hline \multirow[t]{2}{*}{ Musical } & male & 86 & $11.15 \pm 38.83$ & & \\
\hline & female & 71 & $9.56 \pm 36.76$ & 1.23 & .21 \\
\hline Bodily- & male & 86 & $7.71 \pm 35.62$ & & \\
\hline kinesthetic & female & 71 & $8.39 \pm 34.15$ & 1.14 & .25 \\
\hline Logical- & male & 86 & $11.23 \pm 53.53$ & & \\
\hline mathematical & female & 71 & $10.26 \pm 52.52$ & .58 & .55 \\
\hline \multirow[t]{2}{*}{ Spatial } & male & 86 & $11.51 \pm 42.1$ & & \\
\hline & female & 71 & $10.04 \pm 40.76$ & .77 & .44 \\
\hline \multirow[t]{2}{*}{ Linguistic } & male & 86 & $12.13 \pm 61.7$ & & \\
\hline & female & 71 & $12.78 \pm 59.29$ & 1.21 & .22 \\
\hline \multirow[t]{2}{*}{ Interpersonal } & male & 86 & $11.36 \pm 58.44$ & & \\
\hline & female & 71 & $10.8 \pm 58.91$ & .26 & .79 \\
\hline \multirow[t]{2}{*}{ Intrapersonal } & male & 86 & $5.46 \pm 31.74$ & & \\
\hline & female & 71 & $6.87 \pm 30.87$ & .88 & .37 \\
\hline \multirow[t]{2}{*}{ Naturalistic } & male & 86 & $11.32 \pm 33.74$ & & \\
\hline & female & 71 & $29.3 \pm 8.81$ & 2.75 & .007 \\
\hline Multiple & male & 86 & $58.55 \pm 356.09$ & & \\
\hline intelligences & female & 71 & $52.67 \pm 342.94$ & 1.46 & .14 \\
\hline
\end{tabular}

Musical intelligence category contained 14 questions in the MIDAS questionnaire. Each question was assigned a score ranging from zero to five; accordingly, the score domain of the musical intelligence category was from 0 to 70 . Using independent-samples t-test, it was revealed that there is no statistically significant difference between males and females in this type of intelligence $(\mathrm{sig}=.21, p>.05)$.

Bodily-kinesthetic intelligence comprised 13 questions in the MIDAS questionnaire and each question was assigned a score between zero and five. As such, the score domain of this type of intelligence was between 0 and 65 . Results of independent-samples t-test did not reveal any statistically significant difference in the area of bodily-kinesthetic intelligence between males and females ( $\mathrm{sig}=.25, p>.05)$.

For the logical-mathematical intelligence 17 questions were included in the MIDAS with the scores ranging from zero to five. Thus, the score domain for this type of intelligence varied from 0 to 85. Using independent-samples t-test, it was found that like other intelligences, there is not a statistically significant difference between the mean score of male and female students with regard to logical-mathematical intelligence $(\operatorname{sig}=.55, p>.05)$.

For the spatial intelligence 15 questions were devised in the MIDAS questionnaire with the scores ranging from zero to five. So, the score domain for this type of intelligence was from 0 to 75 . Results of independent-samples t-test did not show any statistically significant difference between males and females in the spatial intelligence $(\operatorname{sig}=.44, p>.05)$. 
Regarding verbal-linguistic intelligence, 20 questions were included in the MIDAS questionnaire and the scores ranged from zero to five. Therefore, the score domain for this type of intelligence varied from 0 to 100 . Similar to the previous types of intelligence, results of independent-sample t-test did not show any significant difference between male and females medical students who took part in this study with regard to the verbal-linguistic intelligence $(\operatorname{sig}=.22, p>.05)$.

For interpersonal intelligence 17 questions were included in the MIDAS, and the scores ranged from zero to five. The score domain for this type of intelligence differed from 0 to 80 . The table shows that there is no statistically significant difference between males and females in this regard $(\operatorname{sig}=.79, p>.05)$.

For the intrapersonal intelligence which comprised 9 questions in the questionnaire, the score ranged from zero to five; therefore, the score domain varied from 0 to 45 . Results of independent-samples t-test revealed that there is no statistically significant difference between males and females with respect to intrapersonal intelligence (sig= $.37, p>$ $.05)$.

Naturalistic intelligence encompassed 13 questions in the MIDAS, with the scores ranging from zero to five and the score domain varying from 0 to 65 . Based on the results of independent-samples t-test, it was revealed that at the alpha level of .05 there is a statistically significant difference between male and female medical students who participated in the present study with regard to naturalistic intelligence. In fact, the table indicates that the $p$-value for this type of intelligence is .007 which is less than $.05(p<.05)$.

Finally, regarding the total score for all the questions assessing students' multiple intelligences in the MIDAS a score of 595 was assigned. Considering the results of independent-samples t-test for the MIDAS questionnaire, it was revealed that there is no statistically significant difference between males and females in their multiple intelligences as a whole, and there is gender differences in only one aspect of the multiple intelligences $(\operatorname{sig}=.14, p>.05)$.

Considering the results which were presented in the previous section and with respect to the primary objective of the study, it was found that the dominant intelligence type among the medical students who took part in this study was verbal-linguistic intelligence as it attained the highest mean score among the other intelligences.

Moreover, the results of Pearson correlation test indicated a positive but weak relationship between MI and reading comprehension skill of the medical students. To put it more specifically, in this study it was found that medical students' interpersonal intelligence is correlated with their reading comprehension skill. In addition, it was revealed that there is a positive relationship between reading skill and naturalistic intelligence in male participants and also in all of the participants.

Considering gender differences in multiple intelligence profile of medical students, results of independent-samples t-test indicated that with the exclusion of naturalistic intelligence, as a whole there is no statistically significant difference between male and female medical students in their strength in various types of intelligences.

The study of Hajhashemi, Akef and Anderson (2012) indicated a positive relationship between multiple intelligences and reading proficiency of a group of Iranian EFL students. It also revealed that only in the bodily-kinesthetic intelligence there is a statistically significant difference between male and female participants.

In a similar vein, but taking a broader view, Razmjoo (2008) investigated the relation between MI and language proficiency of Iranian university students and found no relationship between the two variables and stated that none of the intelligences are predictors of language proficiency among the targeted learners. Moreover, the study did not reveal any difference between males and females in this regard.

In line with the studies of Mahdavy (2008), or Akbari and Hosseini (2008), in this study we found that there was a positive relationship between multiple intelligences and reading comprehension ability of a group of Iranian medical students. In another study, McMahon, Rose, and Parks (2004) found that among multiple intelligences only mathematical intelligence correlated with the reading achievement of EFL learners. Based on the literature on multiple intelligences and its association with EFL/ESL learners' language proficiency and specially reading comprehension, it can be inferred that one possible reason for these differing findings might be as a result of differences in the sample. In McMahons Rose, and Parks' study (2004) children were investigated; however, in the present study the university students' multiple intelligences were examined and it is obvious that this sample differs in cognitive style compared to children. As such, through the incorporation of the theory of MI in EFL classrooms students' cognitive style can be directed toward making the best use of their dominant intelligence profile, and at the same time individual differences between students can be catered for. As Richards and Rodgers (2001, p. 118) stated "MI pedagogy focuses on the language classes as the setting for a series of educational support systems aimed at making the language learner a better designer of his/her own learning". Therefore, making learners aware of their intelligences can help them be autonomous and successful learners.

As indicated by Khooei Oskooei and Salahshoor (2014), in teaching reading through differentiated instruction often materials which are interesting to the learners are utilized; however, one way to go beyond 'interest' as a determining factor is using a kind of instruction which takes students' multiple intelligences into account and try to empower the learners with using and improving their strongest intelligence. In this way, the learner will be more cognitively involved in the classroom activities. 
In the present study, the most dominant intelligence types among the medical students were found to be interpersonal, intrapersonal, and naturalistic intelligences. In this regard, it can be argued that by engaging learners in pair or group activities and also reflective thinking these intelligences can be utilized to help them improve in their reading comprehension skill. As stated by Armstrong (2003), intrapersonal intelligence has its origin in the "emotional reactions to the material" (p.19). Accordingly, choosing emotionally appealing materials can help medical students foster their intrapersonal intelligence and also help in developing their reading comprehension skills.

\section{Conclusion}

The literature on MI has revealed its significance in developing EFL/ESL learners' language proficiency and also their language skills. In the presents study, the role of MIT, proposed by Gardner (1983), in General English course of a group of Iranian medical students and its relationship with their reading comprehension ability based on gender was investigated. To this end, a reading comprehension test and the MIDAS questionnaire were utilized. Table 4.1 above demonstrated the MI profile of the participants, revealing that the medical students who took part in this study possess all types of intelligences to some extent with verbal-linguistic intelligence being the most dominant intelligence type $(X$ $=60.61)$.

Results of correlation analysis showed a positive relationship between medical students' MI profile and their reading comprehension skill. However, the relationship was rather weak with the correlation coefficient $(\mathrm{r}=.18, p<.05)$. Accordingly, we can conclude that taking MI of the students into account can help in improving their reading comprehension skills.

Every English language classroom in the Iranian EFL context is usually comprised of male and female students; therefore, paying attention to and considering the probable differences in the cognitive style of males and females is of utmost importance in these classes. This study also tried to take this matter into account and examine the difference in multiple intelligences which might exist in the participants based on gender. As such, with respect to gender differences, the results of independent-samples t-test indicated that there is no statistically significant difference between male and female medical students in their MI profile, except for one of the intelligence types, namely naturalistic intelligence $(\mathrm{p}<.05)$. It can be implied that English teachers need not to be very concerned about the differences in cognitive preferences among male and female medical students and they can implement techniques which address all the students' multiple intelligences.

The findings of this study can have significant implications for EFL teachers and learners. The first point is that, as every medical student possesses different degrees of multiple intelligences, the identification and fostering of their intelligences through designing reading materials which consider their intelligence types can positively influence their success in reading comprehension. As mentioned earlier, in most of General English classes in Iran the focus is on developing students' reading comprehension, as such, teachers should pay attention to the individual students' MI and try to make the best use of their strength to further develop students' reading skill. Moreover, as each learner possesses a varying amount of intelligences, by catering for MI in a single class the teacher would be able to attend students' differing learning style. As to the implications of this study for medical students, raising the learners' awareness of their intelligence types can help them to use their intelligences in developing their academic skills, especially their reading comprehension skill. Syllabus designers and curriculum planners can also make use of the findings in the present study to devise teaching materials that fit medical students' cognitive styles and leads to more efficient and successful learning.

Further studies are needed to explore the probable relationship between the MI profile of medical students and other language skills such as academic writing which is also one of the main requirements in academic contexts. Moreover, as the present study only utilized a questionnaire to probe into the MI profile of medical students, further research can use other instruments to collect more in-depth data with regard to the MI of the learners. Finally, other investigator can examine the relationship between MI and reading comprehension among students majoring in other fields or at different proficiency levels.

\section{References}

Akbari, R., \& Hosseini, K. (2008). Multiple intelligence and language learning strategies: Investigating possible relations. System, 36(2), 141-155.

Armstrong, T. (2003). The multiple intelligences of reading and writing: Making the words come alive. Alexandria: ASCD.

Barchard, K. (2003). Does emotional intelligence assist in the prediction of academic success? Educational and Psychological Measurement, 63, 840-858.

Barzegar, R., Mirtabatabaie, S. M., \& Moradi, H. (2011).On the relationship between multiple intelligences and performance on reading proficiency item types. Iranian EFL Journal, 7(6), 61-78.

Brown, H. D. (2001) Teaching by principles: An integrated approach to language pedagogy (2nd ed.). Longman.

Cook, V. (2001). Second language learning and language teaching ( $3^{\text {rd }}$ ed.).NY: Arnold. 
Gaines, D., \& Lehmann, D. (2002). Improving student performance in reading comprehension through the use of Multiple Intelligences. Master's thesis, Saint Xavier University and Skylight Professional Development Field-based Master's Program. ED467 515.

Gardner, H. (1983). Frames of mind: The theory of multiple intelligences. New York: Basic Books.

Gardner, H. (1999). Intelligence reframed: Multiple intelligences for the 21st century. New York: Basic Books.

Hajhashemi, K., Akef, K., \& Anderson, N. (2012). The relationship between multiple intelligences and reading proficiency of Iranian EFL students. World Applied Sciences Journal, 19(10), 1475-1483.

Hajhashemi. K., \& Eng, W. B. (2012).MI as a predictor of students' performance in reading competency. English Language Teaching, 5(3), 240-251.

Hatch, E., \& Farhady, H. (1982). Research design and statistics for applied linguistics. Tehran: Rahnama Publications.

Jokar, Gh., \& Hesabi, A. (2014). The relationship between multiple intelligence types and L2 reading skill among Iranian high school students. International Journal of Psychology and Behavioral Research, 3(2), 108-116.

Khooei Oskooei, S. (2012). A study of the relationship between multiple intelligences and L2 reading and writing skills among Iranian EFL university students (Unpublished master's thesis). Islamic Azad University of Tabriz, Iran.

Khooei Oskooei, S., \& Salahshoor, F. (2014).The relationship between multiple intelligences and L2 reading Skill among Iranian EFL university students. International Journal of Applied Linguistics and English Literature, 3(5), 229238.

Lazear, D. G. (2004). Multiple intelligence approaches to assessment: Solving the assessment conundrum. UK: Crown House Publishing.

Loori, A. A. (2005). Multiple intelligences: a comparative study between the preferences of males and females. Social Behavior and Personality, 33(1), 77-88.

Mahdavy, B. (2008). The role of multiple intelligences (MI) in listening proficiency: A comparison of TOEFL and IELTS listening tests from an MI perspective. Asian EFL Journal, 10, 109-126.

Mbuva, J. (2003). Implementation of the Multiple Intelligences theory in the 21th century teaching and learning environments: A new tool for effective teaching and learning in all levels. ED 476162.

Mckenzie, W. (2009). Walking the walk: Multiple intelligences in educator professional development. Massachusetts Computer Using Educators, 11-29.

McMahon, S., Rose, D., \& Parks, M. (2004). Multiple intelligences and reading achievement: An examination of the Teele inventory of multiple intelligences. The Journal of Experimental Education, 73, 41-52.

Pishghadam, R. (2009). A quantitative analysis of the relationship between emotional intelligence and foreign language learning. Electronic Journal of Foreign Language Teaching, 6(1), 31-41.

Rahimi, M., Sadighi, F., \& Hosseinyfard, Z. (2011). The impact of linguistic and emotional intelligence on the reading performance of Iranian EFL learners. The Journal of Teaching Language Skills, 3(1), 151-171.

Razmjoo, A. (2008). On the relationship between multiple intelligences and language proficiency. Reading Matrix, 8 , $155-174$.

Richards, J. C. \& Rodgers, T. (2001). Approaches and methods in language teaching (2nd ed.). Cambridge: Cambridge University Press.

Robson, C. (2011). Real world research: A resource for users of social research methods in applied settings. UK: John Wiley \& Sons Ltd.

Shearer, B. (1996). Multiple intelligences developmental assessment scale. Greyden Press.

Shearer, B. (2006). Reading skill and the multiple intelligences: An investigation into the mi profiles of high school students with varying levels of reading skill. Retrieved from http// www.myresearch.org.

Simmons, S. (2001). Multiple intelligences at the middle level: Models for learning in art and across the disciplines. National Art Education Association, 54, 18-24.

Tahriri, A. (2011). On Teaching to Diversity: Investigating the Effectiveness of MI-Inspired instruction in an EFL context. (Unpublished doctoral dissertation). Shiraz University, Iran.

Wiener, H. S., \& Bazerman, C. (2006). Reading skills handbook ( $9^{\text {th }}$ ed.). NY: Pearson Education, Inc. 